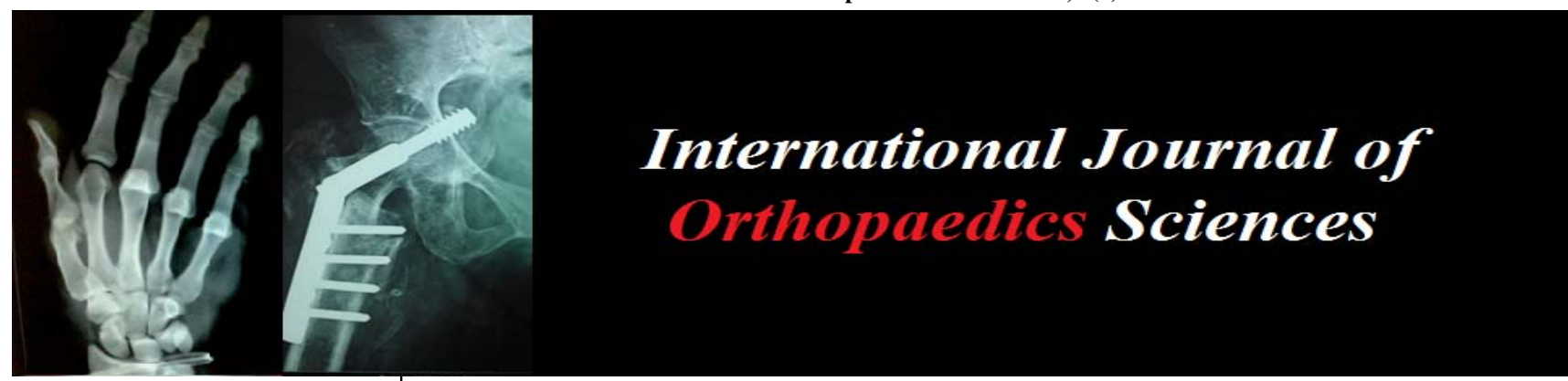

ISSN: $2395-1958$

IJOS 2017; 3(1): 165-171

(C) 2017 IJOS

www.orthopaper.com

Received: 27-11-2016

Accepted: 28-12-2016

Gaurav Kumar

Assistant Professor,

Department of Orthopaedics,

Integral Institute of Medical

Sciences and Research, Lucknow,

Uttar Pradesh, India

\section{Varun Vijay}

Assistant Professor,

Department of Orthopaedics,

Integral Institute of Medical

Sciences and Research, Lucknow,

Uttar Pradesh, India

\section{Nitesh Rathi}

Professor, Department of Orthopaedics, Saveetha Medical College and Hospital, Saveetha

University, Chennai,

Tamil Nadu, India

M Mohan Kumar

Professor, Department of Orthopaedics, Sri Ramchandra Medical College and Research Institute, Chennai, Tamil Nadu, India

\section{Analysis of extra articular proximal third tibial fractures treated with interlocked intramedullary nailing}

\author{
Gaurav Kumar, Varun Vijay, Nitesh Rathi and M Mohan Kumar
}

DOI: $\underline{\text { http://dx.doi.org/10.22271/ortho.2017.v3.i1c.27 }}$

\section{Abstract}

Background: Fractures of the proximal third of tibia shaft have historically higher malunion rates than those of the midshaft. These fractures have been notoriously difficult to treat. With the advent of deepened understanding of the surrounding anatomy, several techniques have been developed to help maintain proper alignment without early failure or malunion.

Aims and Objectives: To study the results of intramedullary interlocking nail fixation in proximal third tibial fractures.

Method: A total of 20 patients were treated with intramedullary interlocking nail fixation and were followed up from 3 months to 3 years and their results were assessed according to Modified Klemm and Borner scoring system.

Results: According to Modified Klemm and Borner scoring system, we had $80 \%$ excellent to fair results and $20 \%$ poor results due to delayed union or non-union at the fracture site.

Conclusion: Interlocked intramedullary nailing of proximal third tibial fractures is an accepted modality of treatment. Stable and adequate intraoperative anatomical reduction is the key to early union and yields superior functional outcome.

Keywords: Tibia fracture, proximal third, intramedullary nailing

\section{Introduction}

Tibial shaft fractures are the most common of all the long bone fractures. Incidence of tibia fractures is nine times more common than femoral fractures. This is because $1 / 3 \mathrm{rd}$ of its surface is subcutaneous throughout its length. Fracture of tibia occurs most commonly in the distal $2 / 3^{\text {rd }}$ of the bone whereas proximal third tibial fractures are relatively uncommon, the incidence of occurrence of proximal third tibial fractures being 5-11\% ${ }^{[1]}$. Non articular proximal third tibial fractures continue to pose vexing problems for orthopedic surgeons due to their high morbidity and treatment dilemma.

Non articular proximal tibial fractures should be distinguished from more distal injuries. These fractures frequently result in malunion with apex anterior and valgus deformity ${ }^{[2,3]}$. There has been continuous debate regarding the classification, management, biology of these fractures. However, selecting the best modality of treatment for the patient is still debatable ${ }^{[4]}$. Several authors have recommended changes to standard intramedullary nailing technique to attempt to prevent malunion in these fractures. These include keeping the knee in semi extended position to decrease the pull of quadriceps on the proximal fragment ${ }^{[5]}$. Using an entry point more lateral than the standard nailing ${ }^{[6]}$.

Understanding the pertinent anatomy, classification systems, diagnostic modalities, and results of treatment with each modality should increase the appreciation of the difficulty of treating a given fracture and help to avoid the complications and pitfalls of various treatment methods. Since not many investigators have reported on such fractures, the current study attempts to analyse such fractures and their outcome with associated complications.

\section{Materials and Methods}

This study was carried out at Sri Ramachandra Medical College And Research Institute, Chennai.

\footnotetext{
Varun Vijay

Assistant Professor,

Department of Orthopaedics,

Integral Institute of Medical

Sciences and Research, Lucknow,

Uttar Pradesh, India
} 
Type of Study: Prospective

Duration: September 2002 till August 2005

Total No of Patients: A total of 20 patients were included in the study

Duration of Follow up: 3 months to $3 y r s$

Mean Follow up: 2 years

\subsection{Inclusion criteria}

- All proximal third tibial fractures treated with interlocking intramedullary nailing

- Fractures of proximal tibia extending to the proximal diaphysis

- Segmental fractures of tibia with proximal fracture in proximal third

- Closed fractures

- Open clean fractures with adequate soft tissue coverage

\subsection{Exclusion criteria}

- Tibial plateau or condylar fractures of tibia

- Proximal third tibial fractures with ipsilateral supracondylar femur fractures (floating knee )

- Open contaminated fractures without soft tissue coverage (Gustilo Anderson grade III A, B and C fractures).

- Proximal third tibial fractures treated by other modalities

- Pathological Fractures

- Patients without Epiphyseal Closure
All patients history was noted with particular importance to mode of injury and associated medical and surgical illness.

Fracture pattern was assessed with X-ray in AP and LATERAL view of the leg with knee and ankle and classified according to the AO classification (Figure 1).

Soft tissue injury pattern were assessed and classified according to the Gustilo Anderson's classification.

Relevant X-rays of any associated bony injuries were taken and further management planned.

All patients were immobilized with Thomas Splint or plaster of paris slab in the Emergency Room as soon as they presented.

All open fractures were given thorough wound wash in Emergency Room and immediately started on I.V. broad spectrum antibiotics

Depending upon the medical conditions, associated injuries and assessing the severity of soft tissue injury, patients were taken up for Interlocked Intramedullary Nailing as early as possible.

In case of delay in surgery patients were immobilized with calcaneal skeletal traction

Time Gap between Injury to Surgery: $<5$ days: 12 Patients

$>5$ days: 8 Patients

Routine AP and Lateral X-rays of the leg including both knee joint and ankle joint

2.3 Length of Nail: Tibial tuberosity to center of tibial plafond on the normal side.

Average surgical Time: $1.5 \mathrm{hrs}$ to $2 \mathrm{hrs}$

All patients were operated under the guidance of Image Intensifier.
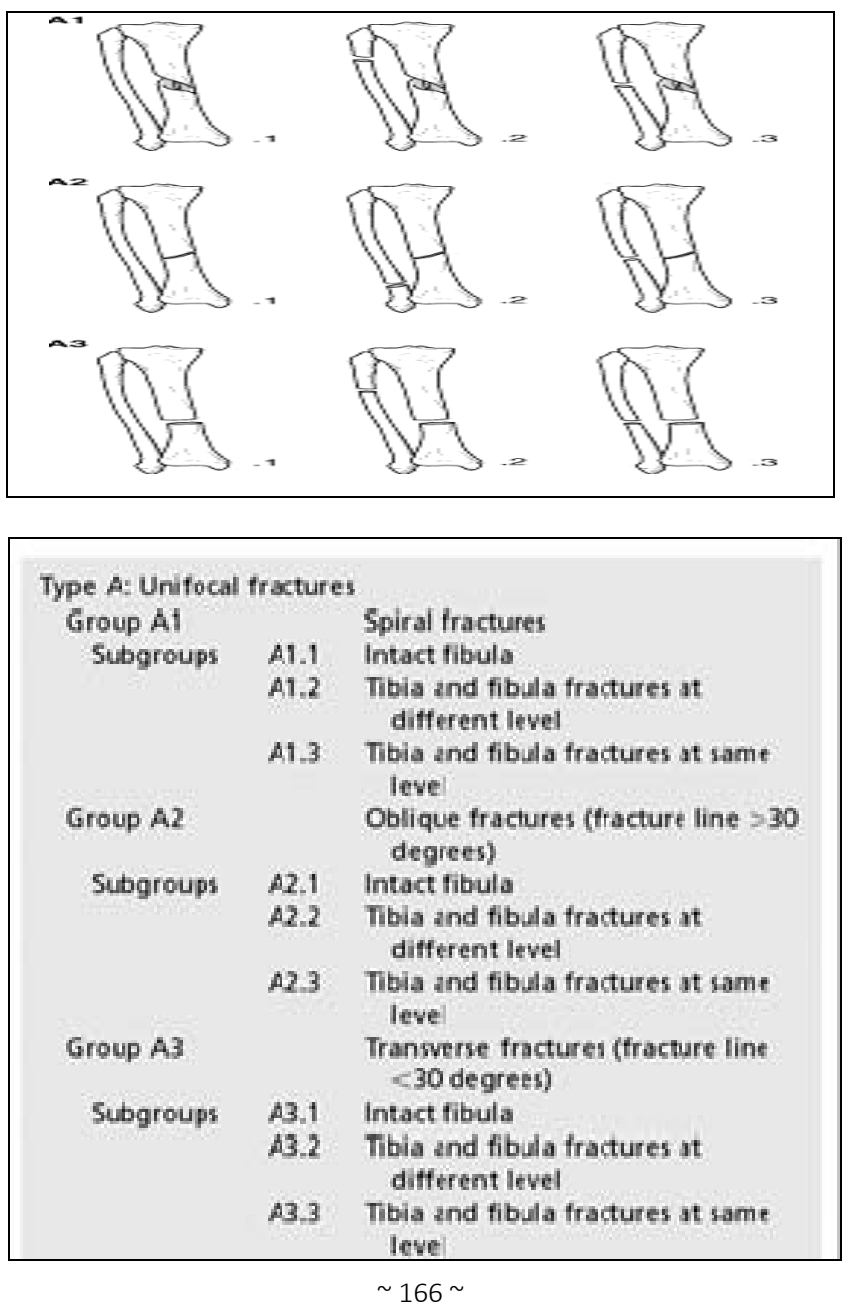


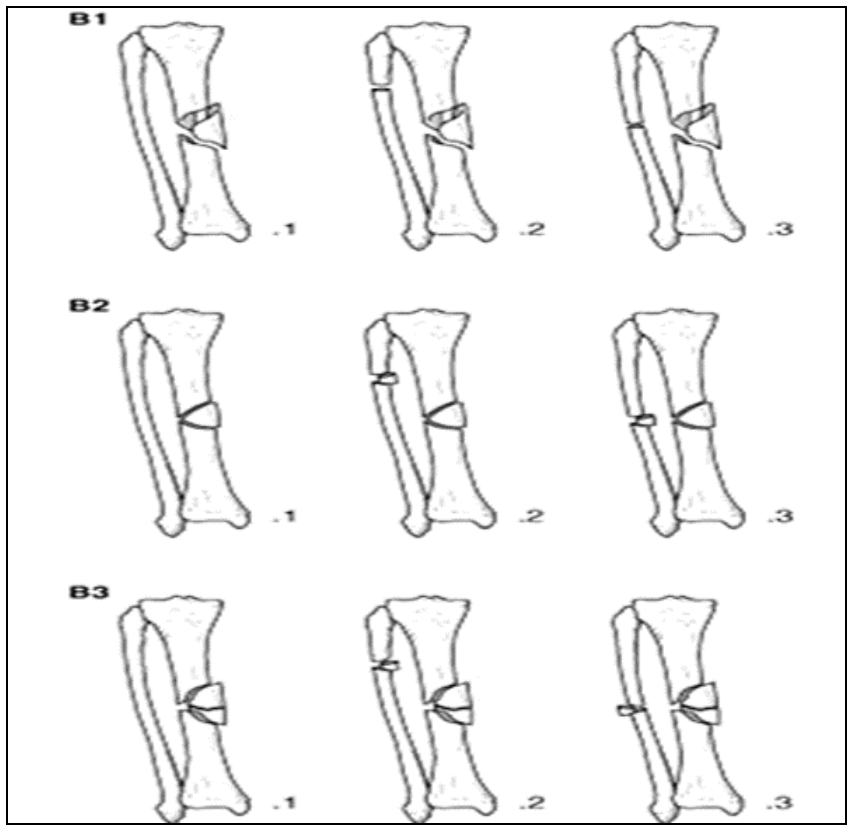

\begin{tabular}{|ccc|c|}
\hline $\begin{array}{c}\text { Type B: Wedge fractures } \\
\text { Group B1 } \\
\text { Subgroups }\end{array}$ & $\begin{array}{c}\text { B1.1 } \\
\text { B1.2 }\end{array}$ & $\begin{array}{c}\text { Intact spiral we dge fractures } \\
\text { Tibia and fibula fractures at } \\
\text { different level }\end{array}$ \\
Troup B2 & B1.3 & $\begin{array}{c}\text { Tibia and fibula fractures at same } \\
\text { level }\end{array}$ \\
Subgroups & B2.1 & $\begin{array}{c}\text { Intact bending wedge fractures } \\
\text { Intact fibula } \\
\text { Tibia and fibula fractures at } \\
\text { different level } \\
\text { Tibia and fibula fractures at same } \\
\text { level } \\
\text { Comminuted wedge fractures } \\
\text { Intact fibula } \\
\text { Subgroups }\end{array}$ & B2.2 \\
B2.1 & B3.2 & $\begin{array}{c}\text { Tibia and fibula fractures at } \\
\text { different level } \\
\text { Tibia and fibula fractures at same } \\
\text { level }\end{array}$ \\
\hline
\end{tabular}

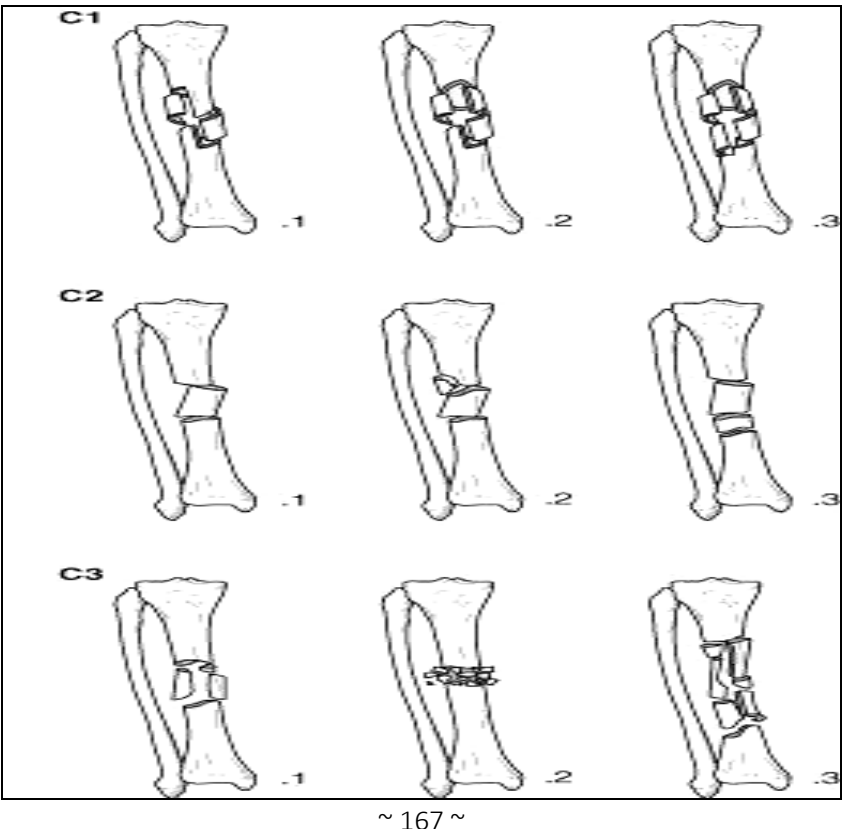




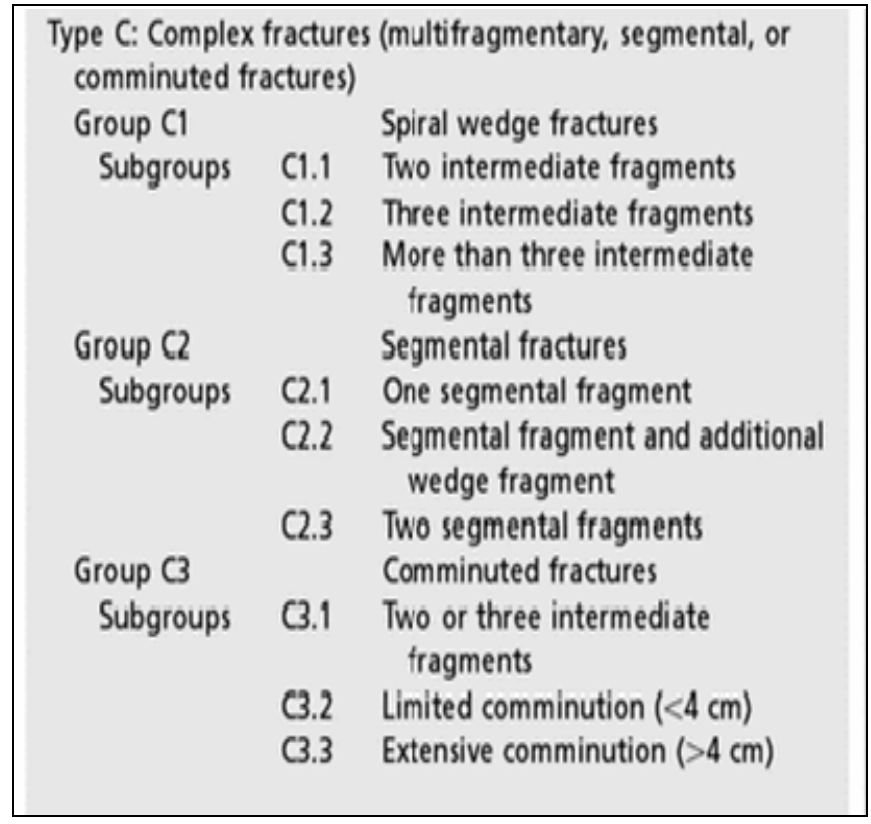

Fig 1: AO classification of proximal third tibial shaft fractures

\subsection{Surgical Technique}

All the patients were operated under spinal anaesthesia in supine position on a non-fracture table with knee bend at 90 degree. The patellar tendon splitting approach was used and reduction achieved by manual or gravity assisted traction method. Entry point for the nail was made in proximal tibial cortex 1 to $1.5 \mathrm{~cm}$ below the joint line above center of tibial tuberosity. Reaming was done in all cases. Proximal locking was done using image intensifier with proximal jig and distal locking with free hand technique.

\subsection{Post-Operative Protocol}

Adequate antibiotic coverage was given to all patients.

Most Patients were started on non-weight bear walking with walker support on 2 nd post-operative day.

Knee Flexion on the 2nd post-operative day after the first wound inspection and satic quadriceps drill

Gradually degree of flexion was increased day by day.

Serial dressings were done on the 2 nd \& 7 th post-operative days.

Suture removal was done on 11th post-operative day and patient discharged.

\subsection{Follow Up Protocol}

Patient was reviewed once in 6 weeks from date of surgery for 3 to 6 months and then 3 months thereafter.

Check X-Rays were taken at each review.

At the end of 6 weeks, patient was allowed partial weight bearing with walker upto 12 weeks post-surgery and Full weight bearing with walker from then on.

At the end of three months if adequate callus formation was there radiologically, patient was allowed to walk without support.

Knee and ankle movements were noted during follow-up.

Patients with associated injuries were ambulated as per their conditions.

The outcome of each patient was analyzed according to the Modified Klemm and Borner scoring system (Table 1)
Table 1: Modified Klemm and Borner scoring system

\begin{tabular}{|c|c|c|c|c|c|}
\hline $\begin{array}{l}\text { Final } \\
\text { Score }\end{array}$ & $\begin{array}{c}\text { ROM } \\
\text { Knee } \\
\text { \&Ankle } \\
\end{array}$ & $\begin{array}{l}\text { Muscle } \\
\text { Atrophy }\end{array}$ & Alignment & Pain & Union \\
\hline Excellent & 4 & 3 & 4 & 4 & 4 \\
\hline Good & 3 & 2 & 3 & 3 & 3 \\
\hline Fair & 2 & 1 & 2 & 2 & 2 \\
\hline Poor & 1 & 0 & 1 & 1 & 1 \\
\hline $\begin{array}{l}\text { Excellent: } \\
\text { Good: } 10-1\end{array}$ & & & $\begin{array}{l}\text { Fair: } 5-9 \\
\text { Poor: } 4-8\end{array}$ & & \\
\hline
\end{tabular}

\subsection{Observations}

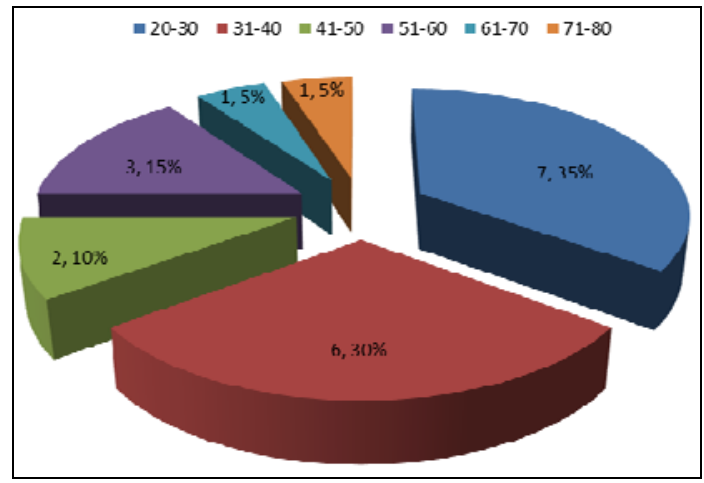

Fig 3: Male- Female Ratio

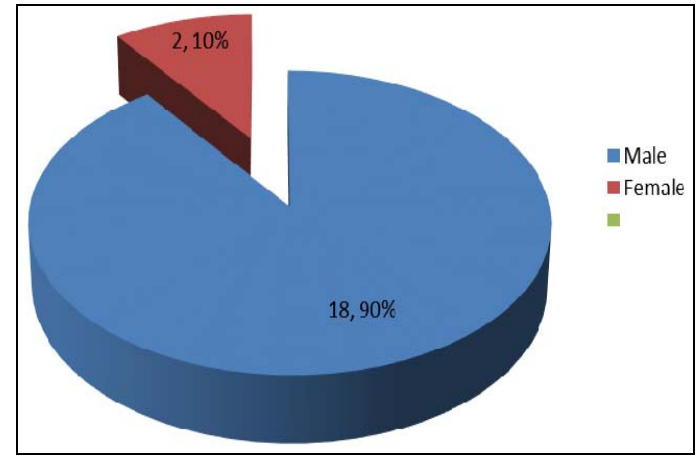

Fig 4: Side of Fracture 


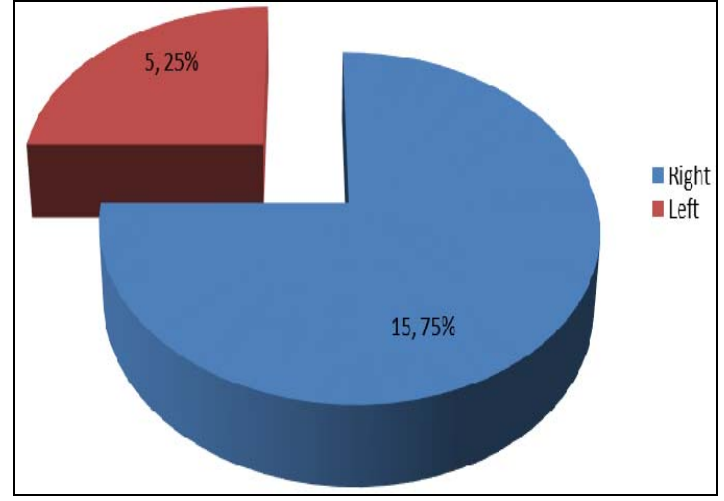

Fig 5: Mode of Injury

Table 2: Type of Fracture

\begin{tabular}{|c|c|c|}
\hline Type Of Fracture & No. of Patients & Percentage \\
\hline Closed & 13 & $65 \%$ \\
\hline Open & 7 & $35 \%$ \\
\hline
\end{tabular}

Table 3: Soft Tissue Injury Pattern (According to Gustilo Anderson's Classification)

\begin{tabular}{|c|c|c|}
\hline Soft Tissue Injury Pattern & No. of Patients & Percentage \\
\hline Grade I & 8 & $40 \%$ \\
\hline Grade II & 12 & $60 \%$ \\
\hline
\end{tabular}

Table 4: Fracture Pattern (According to AO Classification)

\begin{tabular}{|c|c|c|}
\hline Fracture Pattern & No. of Patients & Percentage \\
\hline A1 & 2 & $10 \%$ \\
\hline A2 & 7 & $35 \%$ \\
\hline A 3 & 1 & $5 \%$ \\
\hline B1 & 2 & $10 \%$ \\
\hline B2 & 0 & $0 \%$ \\
\hline B3 & 5 & $25 \%$ \\
\hline C1 & 0 & $0 \%$ \\
\hline C2 & 2 & $10 \%$ \\
\hline C3 & 1 & $5 \%$ \\
\hline
\end{tabular}

Table 5: Complications

\begin{tabular}{|c|c|c|}
\hline Complications & No. of Patients & Percentage \\
\hline Anterior knee pain & 4 & $20 \%$ \\
\hline Restriction of knee ROM & 4 & $20 \%$ \\
\hline Infection (Superficial) & 2 & $10 \%$ \\
\hline Non union & 1 & $5 \%$ \\
\hline Delayed union & 3 & $15 \%$ \\
\hline
\end{tabular}

Table 6: Functional Outcome (According to Modified Klemm and Borner Scoring System)

\begin{tabular}{|c|c|c|}
\hline Result & No. of Patient & Percentage \\
\hline Excellent & 6 & $30 \%$ \\
\hline Good & 3 & $15 \%$ \\
\hline Fair & 7 & $35 \%$ \\
\hline Poor & 4 & $20 \%$ \\
\hline
\end{tabular}

\section{Results}

In our study population, patients were in the age group of 2080 years with the mean age being 36 years (Figure 2 ).

The male to female percentage of our study population was $90 \%$ to $10 \%$ respectively (Figure 3 ).

Right side of the limb was more commonly involved $(75 \%)$ than left side (25\%) (Figure 4).

Road traffic accident (80\%) was most common mechanism of injury in our study population (Figure 5).
Closed fracture constituted $65 \%$ of our study group and the remaining $35 \%$ was open fractures (Table 2).

According to Gustilo Anderson's classification of open fractures we had $40 \%$ grade I and $60 \%$ grade II injuries in our study population (Table 3 ).

According to AO classification of fractures, type A2 was most common (35\%) followed by type B3 (25\%) (Table 4).

Anterior knee pain was the most common complication in our study $(20 \%)$ and all there 4 patients also developed restriction of range of motion at knee joint. 2 patients (10\%) developed superficial wound infection which healed with regular dressing of the wound. 3 patients $(15 \%)$ went into delayed union of the fracture and 1 patient (5\%) went into non-union of the fracture. All these 4 patients were of the open fracture type and that too grade II fracture (Table 5).

According to Modified Klemm and Borner Scoring System we had $80 \%$ excellent to fair results while 4 patients $(20 \%)$ had poor results (Table 6). These were the same 4 patients which went into delayed and non-union.

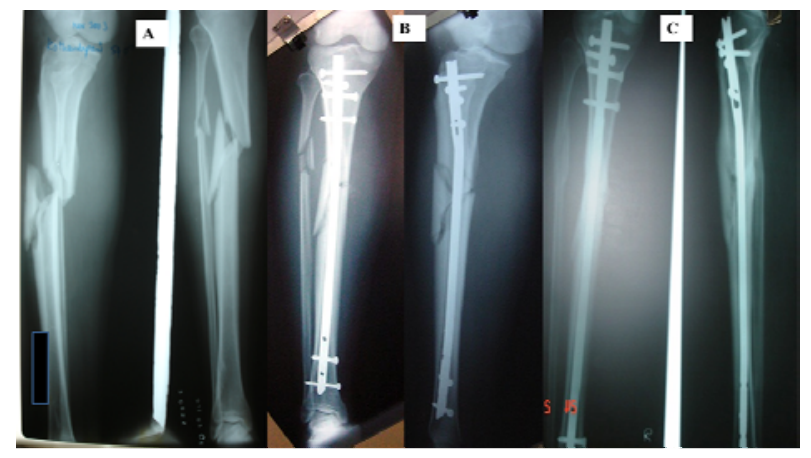

Fig 5A: Pre-operative AP and Lateral view. Fig 5B: Immediate postoperative AP and lateral view. Fig 5C: Final follow up X-ray in AP and lateral view showing fracture healed.

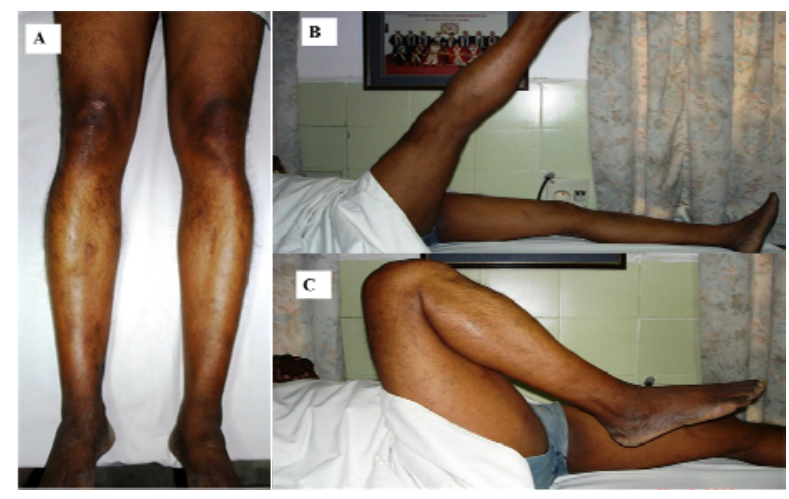

Fig 6A: Clinical photograph of the patient at final follow up. Fig 6B: Extension at the knee joint at final follow up. Fig 6C: Flexion at the knee joint at final follow up.

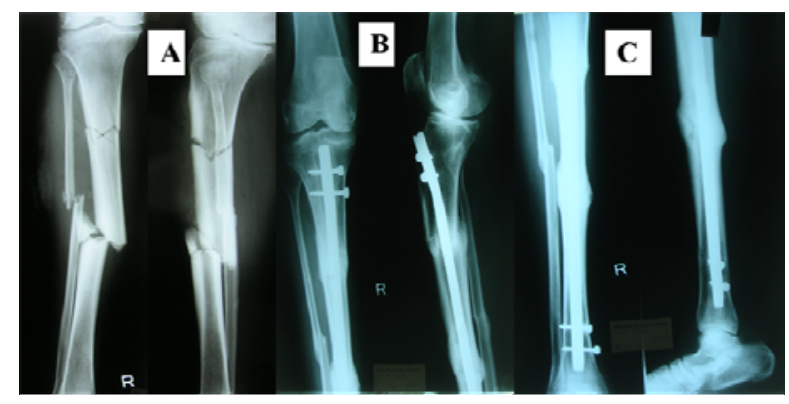

Fig 7A: Segmental fracture upper third tibia. Fig 7 B, C: 1 year postoperative $\mathrm{x}$-rays showing complete fracture healing. 


\section{Discussion}

In our series majority of our cases were less than 40 years of age, the mean age being 36 years. $90 \%$ patients were males because females are less exposed to outdoor activities. In majority of cases, the mode of injury was road traffic accident signifying high velocity injury. Involvement of right leg was more than left side.

In our series time gap between injury and surgery was $<5$ days in 12 cases and $>5$ days in 8 cases. 10 of the 12 cases $(83 \%)$ that underwent early surgery had excellent to good result and superior functional and radiological outcome. Eight cases that underwent surgery $>5$ days period, the functional limitations in these cases were higher.

Lang et al ${ }^{[4]}$ in their series of 32 proximal tibia fractures assessed the functional limitations for 21 patients with 22 fractures, reported $68.18 \%$ of cases with full knee R.O.M. The incidence of cases with $<25 \%$ restriction of knee ROM was $22.72 \%$.In our study $80 \%$ of cases had full knee R.O.M., and the incidence of cases with $<25 \%$ restriction of knee ROM was $20 \%$ (4 patients).

All these 4 cases presented with anterior knee pain. Two cases developed infection (10\%) as an early complication. All these 2 cases were open fractures. In these cases there was instability at fracture site resulting in anterior knee pain, lower knee R.O.M. and subsequent development of infection. In open fractures the rate of infection was higher.

Lang et al $^{[4]}$ in their series showed normal ankle R.O.M. in $64 \%$ of cases, with some degree of restriction in $32 \%$ of cases. In our series there was full ankle R.O.M. in all cases. The incidence of equinus contracture in the series by Lang et al was $4.5 \%$. In our series the incidence of equinus contracture was none.

Paul. J. Duvelius ${ }^{[7]}$ in their series, observed delayed union in $10 \%$ of all closed tibia fractures and in $3 \%$ of proximal tibia fractures. In open fractures incidence of delayed union in all open tibia fractures was $33 \%$ and about $11 \%$ in proximal tibial fractures.

In our series delayed union was observed in 15\% (3 cases) of all cases. Of these all were open fractures. One case underwent additional unicortical plate fixation with bone grafting, one more case underwent bone grafting by the end of 20 weeks as there was no signs of union. Union was achieved after bone grafting in this case.

In our series incidence of non-union was 5\% (1 case). The patient had nonunion due to persistence of fracture gap of $>5 \mathrm{~mm}$ and due to bad comminution and infection. Lang et al reported $6 \%$ incidence of non-union in their series.

Greitbauer et al ${ }^{[8]}$ in their series reported an average union time of 18 weeks for all open fractures of proximal third tibia. In our series time to fracture union averaged 23 weeks in open fractures.

In most of the open fractures union time varied between 12-24 weeks.

3 cases of open fracture had a delayed union ( $\geq 28$ weeks) whereas 1 cases of open fracture had a non-union. Remaining 3 cases of open fracture had an average union time of 22 weeks.

Greitbauer et al ${ }^{[8]}$ in their series reported an average union time of 17 weeks for all closed fractures of proximal third tibia.

In our series time to fracture union averaged 13 weeks in closed fractures

In most of closed fractures union time was early $\leq 12$ weeks

All closed fractures united within 20 weeks

Closed fractures that underwent closed nailing had early union
Most cases that underwent open nailing showed union time at $12-24$ weeks with three cases going for delayed union

Lang et $a^{\left[{ }^{4}\right]}$ in their series noted no infection in all the closed fractures, and $14 \%$ infection rate in the open fractures with two cases of superficial and one case with deep infection.

In our series no infection was noted in all the closed fractures. Among the open fractures rate of infection was $28.5 \%$ ( 2 out of 7 patients) with superficial infection was noted in 2 of our patients. It was seen in patients who had inadequate fixation or had loss of fixation subsequently. In these cases with superficial infection wound debridement followed by antibiotics taken for six weeks the wound subsequently healed with a delayed union of fracture

Wiss et al ${ }^{[9]}$ in their series documented proximal screw backout in $3 \%$ of cases ( 4 cases)

In our series there was no incidence of screw backout.

Vaisto et al ${ }^{[10]}$ reported $67 \%$ of cases with anterior knee pain in their series

Brown et al in their series reported $40.8 \%$ of cases with anterior knee pain

In our series anterior knee pain was observed in 4 cases $(20 \%)$

All cases had pain at nail insertion site with restriction of ROM of knee $<25 \%$.

\section{Conclusion}

Interlocked Intramedullary nailing of proximal third tibial fractures is an accepted modality of treatment.

Stable adequate intraoperative anatomical reduction is the key to early union and yields superior functional outcome.

However favorable clinical and radiological outcome can be achieved by judicious patient selection and avoiding technical errors during surgery.

Interlocked nailing for proximal third tibia fractures is a technically demanding procedure.

Hence a sound knowledge of the technique is a must, lacking which alternative forms of fixations should be considered.

\section{References}

1. Benirschke SK, Henley MB, Ott JW. Proximal one third tibial fracture solutions. Orthop Trans 1995; 18:10551056.

2. Freedman EL, Johnson EE. Radiographic analysis of tibial fracture malalignment following intramedullary nailing. Clin Orthop: 1995; 315:25-32,

3. Bono CM, Levine RG, Rao JP, Behrens FF. Nonarticular Proximal Tibial Fractures: Treatment options and decision making. J Am Acad Orthop Surg; 2001; 9(3):176-186.

4. Lang GJ, Cohen BE, Bosse MJ, Kellam JF. Proximal third tibia shaft fractures should they be nailed? Clin Orthop 1995; 315:64-74.

5. Tornetta IIIP, Collins P, Evans C. Semiextended position of intramedullary nailing of proximal tibia. Clin Orthop; 1996; 328:185-189

6. Buehler KC, Green J, Woll TS, Duwelius PJ. A technique for intramedullary nailing of proximal third tibia fractures. J Orthop Trauma. 1997; 11:218-223,

7. Duwelius PJ, Schmidt AH, Rubinstein RA, Green JM. Nonreamed Interlocked Intramedullary Tibial Nailing One community's Experience. Clin Orthop; 1995; 315:104113.

8. Greitbauer M, Heinz T, Gaebler C, Stoik W, Vecsei V. Unreamed Nailing of Tibial Fractures With the Solid Tibial Nail. Clin Orthop. 1998; 350:105-114.

9. Wiss DA, Stetson WB. Unstable Fractures of the Tibia treated with a Reamed Intramedullary Interlocking nail. 
International Journal of Orthopaedics Sciences

Clin Orthp. 1995; 315:56-63.

10. Vaisto O, Toivanen J, Paakkala T, Jarvela T, Kannus P, Jarvinen M. Anterior knee pain after intramedullary nailing of a tibial shaft fracture. J Orthop trauma. 2005; 19(9):311-316. 